\title{
Cyclic Deformation and Low-Cycle Fatigue for 316LN Stainless Steel under Non-proportional Loading
}

\author{
Yajing Li, Bin Ren, and $X u$ Chen $^{1}$
}

School of Chemical Engineering and Technology, Tianjin University, P. R. China

\begin{abstract}
The effects of loading path and strain amplitude ratio on the cyclic behavior and fatigue life were investigated on a 316LN nuclear grade stainless steel employing a series of symmetrically strain-controlled fatigue tests at room temperature. The loading paths of Uniaxial, Torsional, Proportional, Rhombic, Rectangular, and Circular were employed with the constant equivalent strain amplitude of $0.5 \%$. The strain amplitude ratio of $2.35,1.73$ and 1.27 , defined by the ratio of shear strain amplitude to the axial strain amplitude, was realized by changing the shear strain amplitude under Proportional, Rhombic, Rectangular and Elliptical loading paths. As expected, the significant non-proportional additional hardening was observed. It's interesting to note that the axial cyclic stress response varied with the strain amplitude ratio, and the law was different under different loading paths. The fatigue life of all the tests were evaluated by three critical plane criteria proposed by Smith-Watson-Topper (SWT), FatemiSocie (FS) and Chen-Xu-Huang (CXH). Results show that the SWT criterion significantly overestimated the fatigue life of non-proportional loading because the effect of shear damage was not considered. The CXH criterion for tensile-type failure yielded good prediction results except for two torsional data points. The FS criterion provided better predictions than other models.
\end{abstract}

\section{Introduction}

316LN austenitic stainless steel (ASS) has become the main pipeline material of primary circuit of China's third-generation AP1000 pressurized water reactor nuclear power plant. As structural components, they are often subjected to complex multiaxial fatigue loading owing to the repeated start and stop-operation during service. Therefore, it's of great engineering significance to study the cyclic deformation and suitable fatigue life prediction methods of $316 \mathrm{LN}$ ASS under multiaxial fatigue loading.

Some researchers have studied the cyclic deformation behavior and fatigue behavior of 316 type ASS under cyclic loading. Facheris et al. [1] and Mazánová et al. [2] conducted the strain-controlled fatigue tests of $316 \mathrm{~L}$ ASS subjected to uniaxial, torsional, multiaxial

\section{Corresponding author: xchen@tju.edu.cn}


proportional and multiaxial non-proportional loadings, and found that the larger strain amplitude and non-proportionality of loading path can result in the larger equivalent stress response and shorter fatigue life. Chang and Zhang [1] investigated the cyclic deformation behavior of $316 \mathrm{LN}$ ASS based on the microstructural evolution, and attributed the additional hardening of non-proportional loading to the higher heterogeneity and diversity of dislocation structures. For fatigue life prediction, there are generally three categories of criteria: equivalent strain criteria, critical plane criteria and energy criteria. Among these criteria, the equivalent strain criteria have been reported to perform non-conservatively for multiaxial non-proportional owing to neglecting the non-proportional additional hardening. The energy criterion yielded acceptable life predictions for 316 type ASS subjected to multiaxial cyclic loading [3-5]. Two popular critical plane criteria (FS criterion and SWT criterion) was employed in Ref. [1] to predict the fatigue life of 316L ASS. It's found that the SWT criterion performed well for uniaxial and multiaxial proportional loadings, but it performed poorly for torsional and multiaxial non-proportional loadings. Yet, the prediction result of FS criterion was satisfactory for all the mentioned loadings.

To our knowledge, the research on multiaxial cyclic behavior and fatigue behavior of 316LN stainless steel mainly focused on the strain amplitude and loading path, little on the strian amplitude ratio. Therefore, a series of symmetric strain-control low cycle fatigue (LCF) tests of 316LN ASS were carried out in present work to investigate the effect of loading path and strain amplitude ratio on the cyclic deformation behavior and fatigue life. Furthermore, three classic critical plane criteria were applied to predict the fatigue life under different loadings.

\section{Material and Experiments}

The investigated material was $316 \mathrm{LN}$ stainless steel, with its chemical composition shown in Table 1. The microstructure characterized by optical microscopy (OM) showed austenitic grains with a quantity of annealing twins. The average grain size was about $120 \mu \mathrm{m}$. The mechanical properties under monotonic tensile loading at room temperature (RT) were listed in Table 2.

Table 1. Chemical composition of the $316 \mathrm{LN}$ stainless steel (wt \%).

\begin{tabular}{|c|c|c|c|c|c|c|c|c|c|c|}
\hline $\mathrm{C}$ & $\mathrm{Si}$ & $\mathrm{Mn}$ & $\mathrm{P}$ & $\mathrm{S}$ & $\mathrm{Cr}$ & $\mathrm{Ni}$ & $\mathrm{Mo}$ & $\mathrm{Cu}$ & $\mathrm{N}$ & $\mathrm{Fe}$ \\
\hline 0.016 & 0.270 & 0.810 & 0.008 & 0.008 & 17.52 & 12.12 & 2.39 & 0.08 & 0.065 & Balence \\
\hline
\end{tabular}

Table 2. Mechanical properties under monotonic tensile loading of the $316 \mathrm{LN}$ stainless steel.

\begin{tabular}{|c|c|c|c|}
\hline $\begin{array}{c}\text { Young's modulus, } \\
\mathrm{E}(\mathrm{GPa})\end{array}$ & $\begin{array}{c}\text { Yield strength, } \\
\mathrm{R}_{\mathrm{p}} .2(\mathrm{MPa})\end{array}$ & $\begin{array}{c}\text { Tensile strength, } \\
\mathrm{R}_{\mathrm{m}}(\mathrm{MPa})\end{array}$ & $\begin{array}{c}\text { Elongation, } \\
\delta(\%)\end{array}$ \\
\hline 190 & 292 & 583 & 81 \\
\hline
\end{tabular}

The thin-walled tubular specimens (see Fig. 1) were designed according to the ASTM E2207-02 standard. A series of symmetrically strain-controlled fatigue tests were conducted on an MTS axial-torsional testing system at room temperature with a tension-torsional extensometer of gauge length $25 \mathrm{~mm}$ to measure and control the strain. Table 3 gives the experimental details of all the tests. The fatigue life $\mathrm{N}_{\mathrm{f}}$ is defined as the number of cycles where the axial or shear stress amplitude is reduced by $5 \%$ from the stabilized value. 


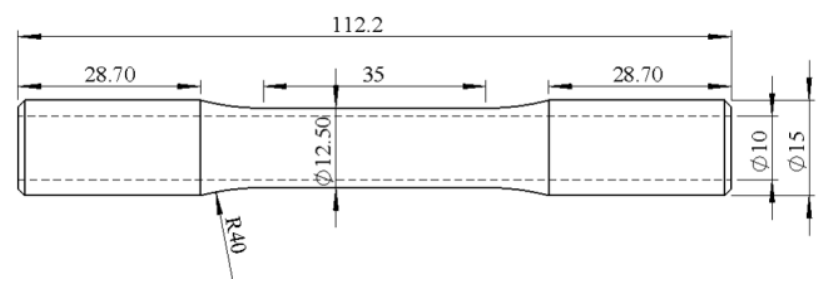

Fig. 1. Tubular specimen geometry of $316 \mathrm{LN}$ stainless steel.

Table 3. Experimental details of $316 \mathrm{LN}$ fatigue tests.

\begin{tabular}{|c|c|c|c|c|c|}
\hline Loading path & $\begin{array}{c}\text { Specimen } \\
\text { ID }\end{array}$ & $\begin{array}{c}\text { Strain } \\
\text { amplitude } \\
\text { ratio, } \lambda\end{array}$ & $\begin{array}{c}\text { Axial } \\
\text { amplitude, } \\
\varepsilon_{\mathrm{a}}(\%)\end{array}$ & $\begin{array}{c}\text { Shear } \\
\text { amplitude, } \\
\gamma_{\mathrm{a}}(\%)\end{array}$ & $\begin{array}{c}\text { Fatigue life, } \\
\mathrm{N}_{\mathrm{f}}\end{array}$ \\
\hline Uniaxial & $\mathrm{U} 1$ & 0 & 0.30 & 0.00 & 30630 \\
\hline Uniaxial & $\mathrm{U} 2$ & 0 & 0.50 & 0.00 & 6345 \\
\hline Uniaxial & $\mathrm{U} 3$ & 0 & 0.60 & 0.00 & 4198 \\
\hline Uniaxial & $\mathrm{U} 4$ & 0 & 0.80 & 0.00 & 2589 \\
\hline Uniaxial & $\mathrm{U} 5$ & 0 & 1.00 & 0.00 & 1035 \\
\hline Torsional & $\mathrm{T} 1$ & $\infty$ & 0.00 & 0.52 & 67788 \\
\hline Torsional & $\mathrm{T} 2$ & $\infty$ & 0.00 & 0.87 & 28402 \\
\hline Torsional & $\mathrm{T} 3$ & $\infty$ & 0.00 & 1.18 & 9822 \\
\hline Torsional & $\mathrm{T} 4$ & $\infty$ & 0.00 & 1.47 & 3556 \\
\hline Torsional & $\mathrm{T} 5$ & $\infty$ & 0.00 & 1.89 & 2834 \\
\hline Torsional & $\mathrm{T} 6$ & $\infty$ & 0.00 & 2.08 & 2312 \\
\hline Proportional & $\mathrm{P} 235$ & 2.35 & 0.35 & 0.83 & 5770 \\
\hline Proportional & $\mathrm{P} 173$ & 1.73 & 0.35 & 0.61 & 11542 \\
\hline Proportional & $\mathrm{P} 127$ & 1.27 & 0.35 & 0.45 & 13620 \\
\hline Rectangular & $\mathrm{R} 235$ & 2.35 & 0.35 & 0.83 & 1563 \\
\hline Rectangular & $\mathrm{Re} 173$ & 1.73 & 0.35 & 0.61 & 1886 \\
\hline Rectangular & $\mathrm{Re} 127$ & 1.27 & 0.35 & 0.45 & 3875 \\
\hline Rhombic & $\mathrm{Rh} 235$ & 2.35 & 0.50 & 1.18 & 1016 \\
\hline Rhombic & $\mathrm{Rh} 173$ & 1.73 & 0.50 & 0.87 & 1453 \\
\hline Rhombic & $\mathrm{Rh} 127$ & 1.27 & 0.50 & 0.64 & 2743 \\
\hline Elliptical & $\mathrm{E} 235$ & 2.35 & 0.50 & 1.18 & 589 \\
\hline Elliptical & $\mathrm{E} 173$ & 1.73 & 0.50 & 0.87 & 675 \\
\hline Elliptical & $\mathrm{E} 127$ & 1.27 & 0.50 & 0.64 & 1273 \\
\hline
\end{tabular}

Note: $\lambda=\gamma_{\mathrm{a}} / \varepsilon_{\mathrm{a}}$.

\section{Results and discussion}

\subsection{Cyclic deformation behavior}

Fig. 2 illustrates cyclic deformation behavior of various loading paths. Fig. 2(a) gives the schematic diagram of loading paths. The equivalent strain amplitudes of the six selected tests were both $0.5 \%$, defined by the von-Mises criterion. Fig. 3(b) and (c) shows the axial stress amplitude and equivalent shear stress amplitude versus number of cycles on a semilogarithmic coordinate system. The equivalent shear stress $\sqrt{3} \tau$ is defined according to the von-Mises criterion. 
(a)

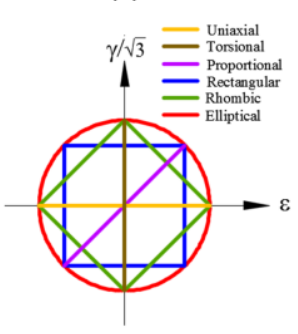

(b)

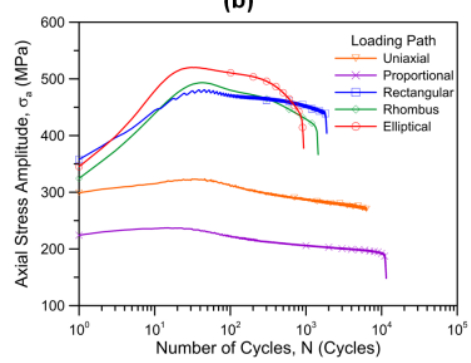

(c)

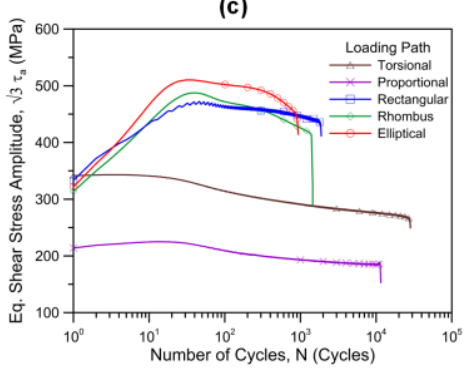

Fig. 2. (a) Schematic diagram of loading paths. The effect of loading path on the (b) axial stress amplitude and (c) equivalent shear stress amplitude with the equivalent strain amplitude of $0.5 \%$.

One can remark that the material exhibited two-staged cyclic stress response regardless of the loading path, initial hardening for the first dozens of cycles, then followed by cyclic softening until final failure. The initial hardening has been reported to relate to an increase of the total dislocation density, whereas cyclic softening is attributed to the movement and re-arrangement of dislocations [6]. For the same equivalent controlled amplitude, the cyclic stress response of Elliptical loading path was the largest, followed by Square or Rhombic, the Uniaxial, Torsional, and finally Proportional loading path. The phenomenon is known as non-proportional additional hardening and has been demonstrated by many authors on 316 type ASS [7, 8].

The effects of strain amplitude ratio, $\lambda$, on the cyclic stress response under Proportional, Rectangular, Rhombic, Elliptical loading paths are represented in Fig. 3. One can note from the schematic diagrams of the loading paths that the axial strain amplitude remains constant but the shear strain amplitude is variable. As expected, the equivalent shear stress amplitude increased with the increasing $\lambda$ because of the larger shear strain amplitude. However, it's not so simple concerning the axial stress response. Although the axial strain amplitude was constant, the axial stress responses were different for different $\lambda$. For the Proportional loading path, the level of axial stress amplitude is the largest for $\lambda$ of 1.27 . While for the other three loading paths, the level of axial stress amplitude is the smallest for $\lambda$ of 1.27.

\subsection{Fatigue life prediction}

For uniaxial and torsional fatigue tests, the relationship between strain amplitude and the fatigue life is obtained by Manson-Coffin equation:

$$
\begin{aligned}
& \varepsilon_{\mathrm{a}}=\frac{\sigma_{\mathrm{f}}^{\prime}}{\mathrm{E}}\left(2 \mathrm{~N}_{\mathrm{f}}\right)^{\mathrm{b}}+\varepsilon_{\mathrm{f}}^{\prime}\left(2 \mathrm{~N}_{\mathrm{f}}\right)^{\mathrm{c}} \\
& \gamma_{\mathrm{a}}=\frac{\tau_{\mathrm{f}}^{\prime}}{\mathrm{G}}\left(2 \mathrm{~N}_{\mathrm{f}}\right)^{\mathrm{b}_{0}}+\gamma_{\mathrm{f}}^{\prime}\left(2 \mathrm{~N}_{\mathrm{f}}\right)^{\mathrm{c}_{0}}
\end{aligned}
$$

where $\varepsilon_{\mathrm{a}}$ and $\gamma_{\mathrm{a}}$ are uniaxial strain amplitude and torsional strain amplitude, respectively, $\sigma_{\mathrm{f}}{ }^{\prime}$ is axial fatigue strength coefficient, $\mathrm{b}$ is axial fatigue strength exponent, $\varepsilon_{\mathrm{f}}$ ' is axial fatigue ductility coefficient, $\mathrm{c}$ is axial fatigue ductility exponent, $\tau_{\mathrm{f}}$ ' is shear fatigue strength coefficient, $\mathrm{b}_{0}$ is shear fatigue strength exponent, $\gamma_{\mathrm{r}}^{\prime}$ is shear fatigue ductility coefficient, $\mathrm{c}_{0}$ is shear fatigue ductility exponent, $2 \mathrm{~N}_{\mathrm{f}}$ are reversals to failure, $\mathrm{E}$ is the Young's modulus, and $\mathrm{G}$ is the shear modulus. The corresponding values of 316LN ASS are listed in Table 4. 


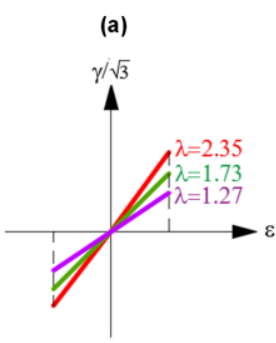

(d)

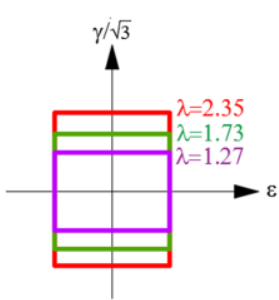

(g)

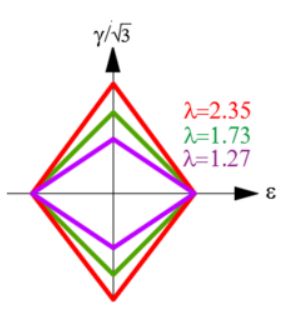

(j)

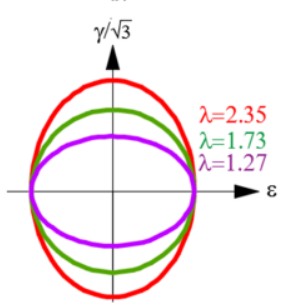

(b)

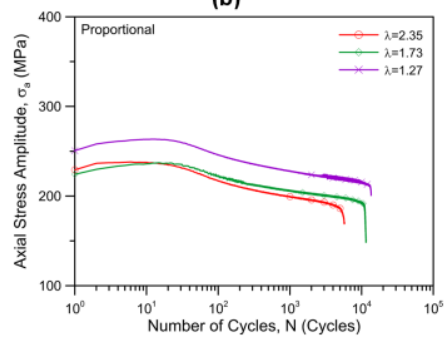

(e)

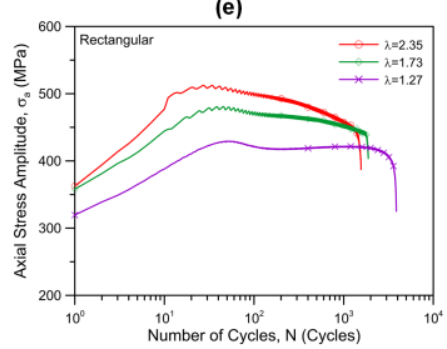

(h)

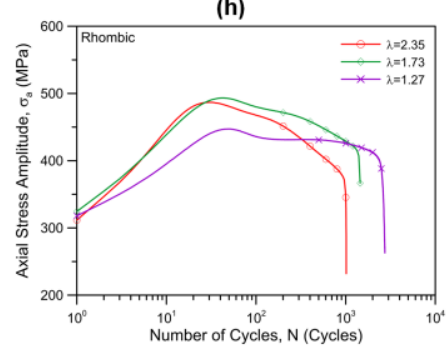

(k)

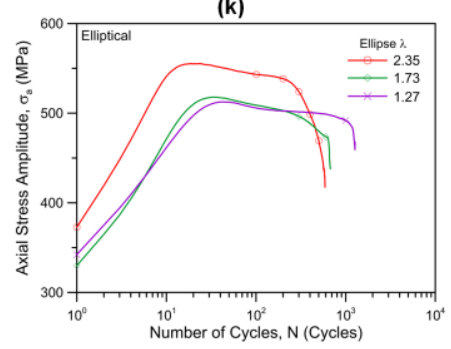

(c)

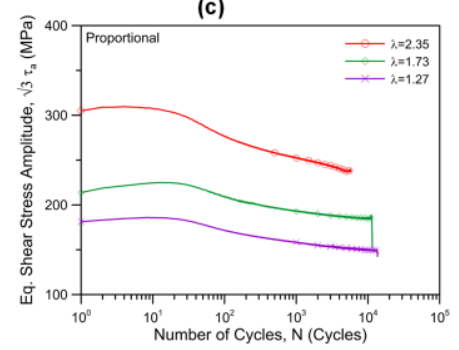

(f)

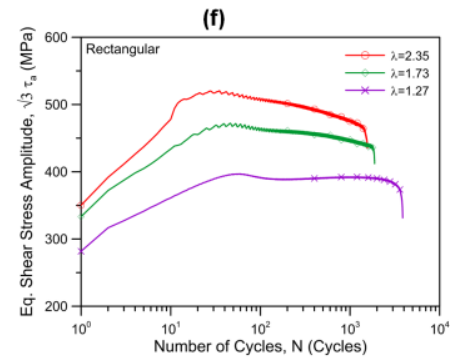

(i)

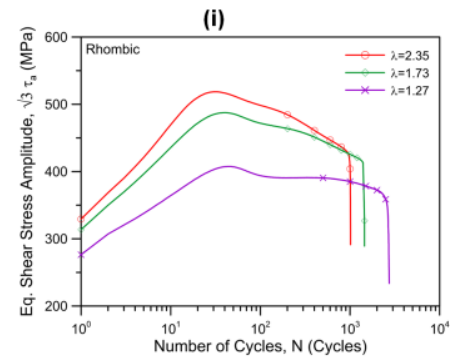

(I)

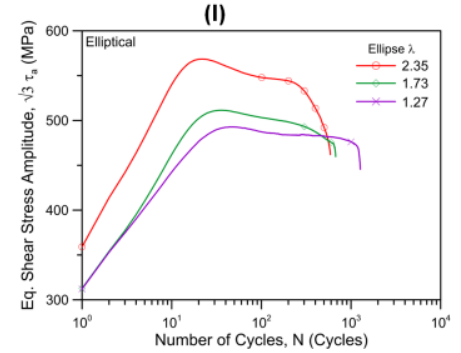

Fig. 3. The effect of strain amplitude ratio, $\lambda$, on the axial stress amplitude and equivalent shear stress amplitude subjected to (a-c) Proportional (d-f) Rectangular (g-i) Rhombic (j-l) Elliptical loading path. $(\mathrm{a})(\mathrm{d})(\mathrm{g})(\mathrm{j})$ are schematic diagrams, $(\mathrm{b})(\mathrm{e})(\mathrm{h})(\mathrm{k})$ are axial stress amplitude responses, $(\mathrm{c})(\mathrm{f})(\mathrm{i})(\mathrm{l})$ are equivalent shear stress amplitude responses.

Table 4. Fatigue properties of 316 LN ASS.

\begin{tabular}{|c|c|c|c|}
\hline \multicolumn{2}{|c|}{ Uniaxial properties } & \multicolumn{2}{c|}{ Torsional properties } \\
\hline $\mathrm{E}(\mathrm{GPa})$ & 190 & $\mathrm{G}(\mathrm{GPa})$ & 79 \\
\hline Fatigue strength coefficient, $\sigma_{\mathrm{f}}{ }^{\prime}(\mathrm{MPa})$ & 1163.8 & Fatigue strength coefficient, $\tau_{\mathrm{f}}{ }^{\prime}(\mathrm{MPa})$ & 688 \\
\hline Fatigue strength exponent, $\mathrm{b}$ & -0.142 & Fatigue strength exponent, $\mathrm{b}_{0}$ & -0.135 \\
\hline Fatigue ductility coefficient, $\varepsilon_{\mathrm{f}}{ }^{\prime}$ & 0.315 & Fatigue ductility coefficient, $\gamma_{\mathrm{f}}{ }^{\prime}$ & 0.766 \\
\hline Fatigue ductility exponent, $\mathrm{c}$ & -0.47 & Fatigue ductility exponent, $\mathrm{c}_{0}$ & -0.451 \\
\hline
\end{tabular}


In the present work, three critical plane criteria, including Fatemi-Socie (FS) criterion, Smith-Watson-Topper (SWT) criterion, and Chen-Xu-Huang (CXH) criterion, were employed to evaluate the multiaxial fatigue life of $316 \mathrm{LN}$ ASS.

Fatemi and Socie [9] thought that the shear damage is the main factor of fatigue damage, and meanwhile considered the contribution of the maximum normal stress. The criterion is presented below:

$$
\mathrm{P}_{\mathrm{FS}}=\gamma_{\mathrm{c}, \text { ampl }}\left(1+\mathrm{k} \frac{\sigma_{c, \text { max }}}{\sigma_{y}}\right)=\frac{\tau_{f}^{\prime}}{G}\left(2 N_{f}\right)^{b}+\gamma_{f}^{\prime}\left(2 N_{f}\right)^{c}
$$

where $\gamma_{\mathrm{c} \text {,ampl }}$ is the shear strain amplitude of the critical plane, $\sigma_{\mathrm{c}, \max }$ is the maximum normal stress of the critical plane, $\sigma_{\mathrm{y}}$ is the yield stress of the material, $\mathrm{k}$ is a material parameter to consider the tensile damage of maximum shear strain plane. The value of $\mathrm{k}$ was calculated to be 1.38 by fitting the uniaxial fatigue tests.

Smith, Watson and Topper [10] proposed a fatigue life prediction criterion based on tensile failure (SWT). The critical plane is the plane experiencing the maximum normal strain amplitude. The damage parameter can be described as follows:

$$
\mathrm{P}_{\mathrm{SWT}}=\varepsilon_{\text {ampl }} \sigma_{\max }=\frac{\sigma_{f}^{\prime 2}}{E}\left(2 N_{f}\right)^{2 b}+\sigma_{f}^{\prime} \varepsilon_{f}^{\prime}\left(2 N_{f}\right)^{b+c}
$$

where $\varepsilon_{\mathrm{ampl}}$ is the normal strain amplitude of the critical plane, $\sigma_{\max }$ is the maximum normal stress of the critical plane.

Chen et al. [11] considered that both tensile and shear components on the critical plane will contribute to the fatigue damage. So a criterion $(\mathrm{CXH})$ considering both normal and shear strain energies was put forward. Meanwhile, they proposed two different damage parameters for shear-type failure and tensile-type failure. For the shear-type failure mechanism, the criterion $(\mathrm{CXH}(\mathrm{S}))$ is given by the equation:

$$
\mathrm{P}_{\mathrm{CXH}(\mathrm{S})}=\gamma_{\max } \tau+\varepsilon_{\mathrm{n}} \sigma_{n}=\frac{\tau_{f}^{\prime 2}}{G}\left(2 N_{f}\right)^{2 b_{0}}+\tau_{f}^{\prime} \gamma_{f}^{\prime}\left(2 N_{f}\right)^{b_{0}+c_{0}}
$$

where $\gamma_{\max }$ is the maximum shear strain amplitude, $\tau_{1}, \varepsilon_{\mathrm{n}}$, and $\sigma_{\mathrm{n}}$ are the amplitudes of the shear stress, normal strain and normal stress in the critical plane, respectively. For the shear-type failure, the critical plane is defined as the plane with maximum shear strain amplitude. For the tensile-type failure mechanism, the criterion $(\mathrm{CXH}(\mathrm{T}))$ changes to:

$$
\mathrm{P}_{\mathrm{CXH}(\mathrm{T})}=\varepsilon_{1} \sigma_{1}+\gamma_{1} \tau_{1}=\frac{\sigma_{f}^{\prime 2}}{E}\left(2 N_{f}\right)^{2 b}+\sigma_{f}^{\prime} \varepsilon_{f}^{\prime}\left(2 N_{f}\right)^{b+c}
$$

where $\varepsilon_{1}$ is the maximum normal strain amplitude, $\sigma_{1}, \gamma_{1}$ and $\tau_{1}$ are the amplitudes of the normal stress, shear strain and shear stress, respectively, in the critical plane. For the tensile-type failure, the critical plane is defined as the plane with maximum normal strain amplitude.

Figure 4 displays the result of fatigue life prediction by the mentioned three criteria. Figure 4(a) shows that all of the predictions by FS criterion are within the life factor of 2 bands, which agrees with the results of $316 \mathrm{~L}$ ASS in Ref. [1]. It's owing to the fact that FS criterion takes the shear strain amplitude as the main fatigue parameter and considers the effect of maximum normal stress on the fatigue damage. Figure 4(b) gives the result of fatigue life prediction by SWT criterion. It is shown that the SWT criterion performs well for fatigue life prediction under uniaxial, torsional and proportional loadings. But for nonproportional (Rectangular, Rhombic and Elliptical) loadings, the prediction results are nonconservative. This is owing to the fact that only normal strain energy is included in the SWT criterion, and the effect of shear strain energy on the fatigue damage is not taken into account. Figure 4(c) and (d) shows the fatigue life prediction results obtained by $\mathrm{CXH}(\mathrm{S})$ and $\mathrm{CXH}(\mathrm{T})$ criteria. For $\mathrm{CXH}(\mathrm{S})$ criterion, it performs well under torsional and 
Rectangular loadings, but the results are very non-conservative for the other four loadings. While for $\mathrm{CXH}(\mathrm{T})$ criterion, most of the predictions are within the life factor of two except two torsional tests.

(a)

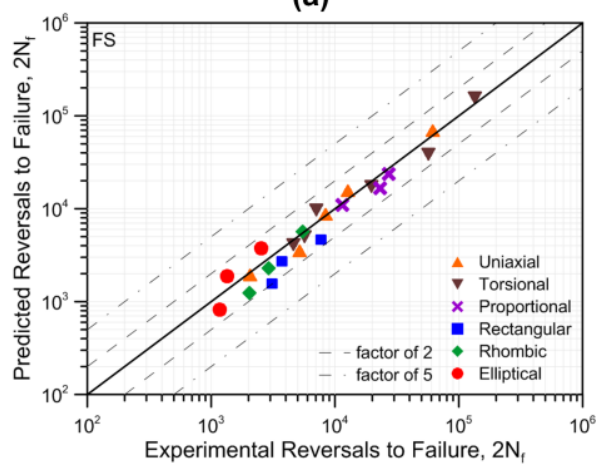

(c)

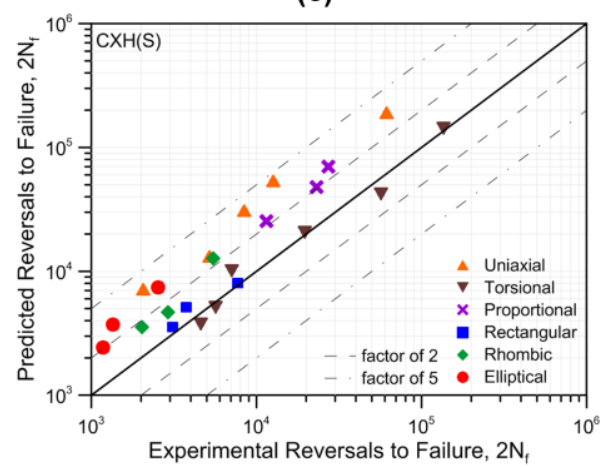

(b)

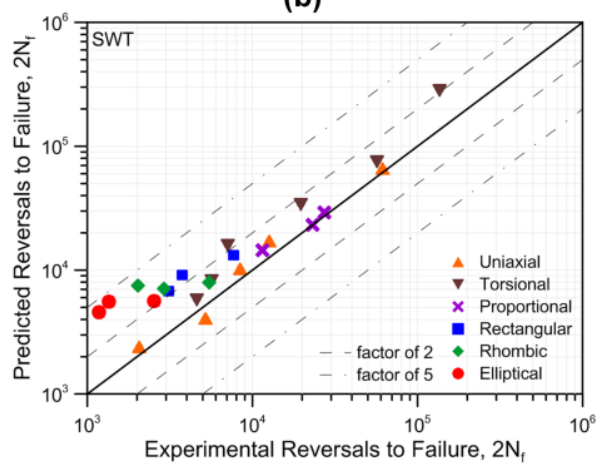

(d)

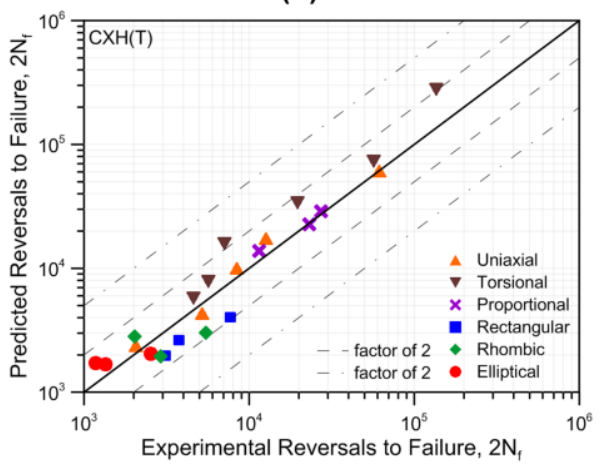

Fig. 4. The fatigue life prediction results by (a) FS (b) SWT (c) $\mathrm{CXH}(\mathrm{S})$ (d) $\mathrm{CXH}(\mathrm{T})$ criterion.

\section{Conclusions}

A series of cyclic tests on a $316 \mathrm{LN}$ ASS were carried out to investigate the effect of the loading path and strain amplitude ratio on cyclic deformation behavior and fatigue behavior. The non-proportional additional hardening was observed. The strain amplitude ratio can make a different influence on the axial cyclic stress response for various loading paths. Three fatigue life prediction criteria, SWT, FS and CXH were employed for fatigue life prediction. It is shown that the SWT criterion and CXH criterion for shear-type failure perform poorly for non-proportional loadings. While the FS criterion and CXH criterion for tensile-type failure can provide acceptable prediction results for most of experiments.

This work was supported by the National Natural Science Foundation of China (Grant number 51435012).

\section{References}

1. G. Facheris, K.G.F. Janssens, S. Foletti. Int. J. Fatigue 68, 195-208 (2014)

2. V. Mazánová, V. Škorík, T. Kruml, J. Polák. Int. J. Fatigue 100, 466-476 (2017)

3. K.C. Liu, J.A. Wang. Int. J. Fatigue 23, 129-134 (2001)

4. E.S. Feng, X.G. Wang, C. Jiang. Int. J. Fatigue 122, 1-8 (2019) 
5. H. Zhu, H. Wu, Y. Lu, Z. Zhong. Int. J. Fatigue 121, 1-8 (2019)

6. M.S. Pham, C. Solenthaler, K.G.F. Janssens, S.R. Holdsworth. Mater. Sci. Eng., A 528, 3261-3269 (2011)

7. A. Benallal, P. Le Gallo, D. Marquis. Nucl. Eng. Des. 114, 345-353 (1989)

8. E. Tanaka, S. Murakami, M. Ōoka. J. Mech. Phys. Solids 33, 559-575 (1985)

9. A. Fatemi, D. Socie. Fatigue Fract Eng M 11, 149-165 (1988)

10. K.N. Smith, P.Waston, T.H. Topper. J. Mater 5, 767-78 (1970)

11. X. Chen, S. Xu, D. Huang. Fatigue Fract Eng M 22, 679-686 (1999) 